\title{
Innovation of Customer Chemicals Packaging in Concern of Sustainability
}

\author{
Lenka BRANSKA ${ }^{1, *}$, Michal PATAK ${ }^{2}$ and Zuzana PECINOVA ${ }^{3}$ \\ 1 University of Pardubice, Pardubice, Czech Republic; lenka.branska@upce.cz \\ 2 University of Pardubice, Pardubice, Czech Republic; michal.patak@upce.cz \\ 3 University of Pardubice, Pardubice, Czech Republic; zuzana.pecinova@upce.cz \\ * Correspondence: lenka.branska@upce.cz
}

\begin{abstract}
Increasing the environmental orientation of manufactured products and business activities is becoming the current trend in the area of corporate management. Logistics activities and the packaging of products are also becoming focal points as they have significant potential to reduce the environmental burden. Great attention is paid to primary packaging, especially if the company uses plastic packaging. The article deals with the possibilities of primary packaging innovation for selected consumer chemical products in order to reduce the volume of used plastics. Possibilities of innovation were identified by content analysis of information obtained in primary qualitative research in a medium-sized company engaged in the production of consumer chemical products. It has been found that the reduction of plastic packaging waste for a selected product can be achieved by replacing the plastic with another material, changing the colour of the plastic packaging, using recycled plastics in packaging production, changing the packaging production technology, through innovations of the packaged product, changes in the management of the sales process, introduction of a plastic packaging reuse system and application of recycling. However, the implementation of individual innovations always means an increase in operating costs, some of which will also require investment costs.
\end{abstract}

Keywords: supply chain management; packaging; chemical product

JEL Classification: M11; M21

\section{Introduction}

Today's world is characterized by a turbulent market environment and the search for ways to increase competitiveness. This aspect, together with society's growing interest in environmental protection, is making the concept of sustainability increasingly popular (González-Boubeta et al. 2018). Business entities tend to improve the activities carried out on the basis of this concept. They focus on improving a range of activities, much attention is paid to supply chain management activities. Improvement can concern any of the three pillars of sustainability. The most studied in sustainable supply chain management are the economic and environmental dimensions (Bendul et al. 2017), while the social aspect is usually left aside (González-Boubeta et al. 2018). According to Abdullah et al. (Abdullah et al. 2018) green supply chain management is essential for the enterprise's sustainability. Environmental aspects of supply chain management should be particularly addressed in achieving logistic excellence in the 21st century (Karia and Asaari 2013).

Environmental aspects are associated with both direct flow (shipping from producer-to-end user movements), and reverse flow (end user-to-producer movements - reverse logistics). Both of these flows affect environmental performance. Thus, in order to improve environmental performance, attention must be paid to the activities involved in these flows, in particular to activities related to transports, storage or warehousing, inventory management, packaging and materials handling (Karia and Asaari 2013). Packaging provides a great opportunity to increase environmental performance.

The authors (Saghir 2002; García-Arca and Prado-Prado 2008; Bramklev 2009) identify three main requirements that exist in the design of packaging - business requirement, logistic requirement and environmental protection requirement. From a commercial and logistical point of view, packaging in the 
supply chain plays an important role by providing customers with information about the product (size, weight, colour, content, density), but also by minimizing product loss and damage at various stages of distribution. At the same time, it facilitates efficient storage and handling. However, the environmental protection requirement makes businesses also focus on the environmental aspects of packaging (Dharmadhikari 2012). Packaging is not just a carton or a box, but a system that enables safe, cost-effective storage, handling, transportation and marketing support (Dixon-Hardy and Curran 2009), while respecting environmental requirements. Some authors describe the development of the right packaging as an indispensable activity in building sustainable supply chain management (Mejías et al. 2016), as a strategic element in achieving the economic and environmental performance of the enterprise (GonzálezBoubeta et al. 2018).

Plastics are a major environmental problem associated with packaging. They are often disposable multi-layer plastics that cause unsustainable consumption and environmental burdens (Meherishi et al. 2019). Therefore, packaging innovation to reduce plastics can be a very significant environmental improvement. At the same time, such an innovation can significantly contribute to strengthening customer relations, especially if they are large retailers. They want better environmental performance and ever-lower prices without sacrificing product quality. Therefore, they constantly put pressure on suppliers to invest in reducing packaging and energy consumption (Yenipazarli 2017).

Reducing the volume of plastic packaging is of particular interest to the food industry, which produces large volumes of plastic disposable packaging for everyday products. In other sectors, interest in the same is beginning to develop. Not surprisingly, manufacturers of consumer chemicals are also interested in reducing plastic packaging. Like food businesses, they produce products bought relatively often at relatively reasonable prices, packaged in standard plastic packaging. Innovation in the packaging of consumer chemical products can bring significant environmental benefits. Examples of practical innovations in this field are already known. For example, P\&G has developed 2X" versions of their products to meet its customer's (Wal-Mart) requirements on liquid laundry detergents (packaging the same number of loads into a half-sized bottle) (Makower and Pike 2009). The same company uses sugar cane-derived plastic packaging for its Pantene Pro-V brand in the Western Europe region. The raw material for packaging is produced by a process that transforms sugar cane into ethanol by fermentation. Ethanol is further converted to ethylene by a polymerization process and subsequently to a high-density polyethylene plastic (Dharmadhikari 2012). In 2006, Unilever also introduced a detergent in a concentrated form. Using the concentrate, consumers could wash the same volume of garments with one third of the product. This resulted in significant savings in packaging material, with effects also on product storage (Atkinson 2008).

There are certainly more ways to innovate plastic packaging for consumer chemical products. Variants may be associated not only with the innovation of the product itself, but also with changes in packaging material or weight. Recycling systems for plastics used for packaging consumer chemical products or systems for the reuse of such packaging can also contribute to sustainability. The aim of the article is to define the possibilities of reducing the volume of plastic used to package a selected consumer chemical product. The aim of the article will be achieved through primary qualitative research, which was carried out in a medium-sized enterprise of the chemical industry.

The main outputs of the article will serve as a contribution to the identification of possibilities to reduce the volume of plastic containers used for consumer chemical products. These outputs will enrich theoretical knowledge in the field of packaging sustainability, but can also directly serve businesses producing consumer chemical products to manage innovations of the plastic packaging of their products.

\section{Theoretical definition of plastic packaging innovations in the interest of sustainability}

Innovation of packaging to reduce the volume of produced and disposable plastics is a typical green innovation. It allows to reduce the amount of consumed resources and produced waste (especially from packaging) and various other, e.g. energy losses. It can be connected to any stage of production of packaging, its use and removal, i.e. the process of packaging production, packaging itself, distribution of products in the packaging, commercialization of the product (García-Arca et al. 2014), packaging reverse flow or recycling. 
Environmentally oriented packaging innovations can be classified in two groups, namely (Karia and Asaari 2013):

- technical and technological,

- non-technological and administrative.

Technical and technological innovations may include all changes related to the production of the packaging or the product packaged therein. This group of innovations includes eco-friendly packaging design, saving material and energy resources in packaging production (Chen et al. 2006; Chen 2008) or reducing packaging volume in one-off sales.

The design of eco-friendly packaging may include:

- replacement of plastics with environment-friendly material (relatively easy-to-recycle material, e.g. paper, biodegradable material, e.g. starch, corn, sugar cane, or reusable, e.g. glass) (Liwen and Juan 2010; Dharmadhikari 2012),

- replacement of plastics with recycled plastics,

- adjustment of packaging size and/or weight. This group of innovations also includes technological changes in the production of packaging, e.g. removal of unnecessary packaging layers (Karia and Asaari 2013) or reduction of packaging density, e.g. by bubbling (by injecting gas to create gas bubbles in the middle layer of the bottle wall) (Magnier and Schoormans 2015).

Energy saving is related to technological innovations associated mainly with packaging production. In this context, it is not only energy savings, but generally any resource savings in packaging production, including the use of secondary sources for production (recycled materials as inputs, secondary energy or energy that comes from renewable sources) (Dharmadhikari 2012).

Reducing the volume of the packages may be associated with reducing the size of the packaging as a result of modification of the product placed therein, or also in the case of greater use of the package (e.g. the air layer is reduced). This may also reduce the number of re-purchases of products in plastic packaging.

Non-technological and administrative innovations may include changes in processes and techniques (including changes in business and transport processes), greening of supply, changes in customer relationship management, knowledge management (Karia and Asaari 2013), but also changes in the hardware and software used to manage environmental innovation (Flint et al. 2005). This group of innovations may also include the setting up of a packaging recycling system or its modification, the introduction of a packaging reuse system (including re-use for another purpose), but also the introduction of environmental management of the business (Chen et al. 2006; Chen 2008) and implementation of joint clean technology programmes with suppliers and customers (Karia and Asaari 2013).

\section{Methodology}

The primary research in the medium-sized enterprise of the chemical industry was carried out as qualitative. The main objective of the research was to identify the possibilities of reducing the volume of plastic waste from the primary packaging for the selected product. The product selected was a detergent intended for cleaning and refreshing toilets. It consists of a cleaning gel in a cylindrical container and a dispenser (extrusion piston). The gel is applied by the dispenser, i.e. pushed in a measured amount, directly onto the sanitary equipment (toilet). It is gradually released with flushing.

The research focused on the possibility of saving plastic, which is used both for the container containing the gel and for the extrusion piston. The information was collected by personal interviewing according to an interviewing scenario. The interview scenario included the following areas of inquiry:

- The form of innovation process in the company. Forms of cooperation with business partners in technical and technological innovations.

- Possibilities of packaging innovation to reduce plastic for the selected product:

o Saving plastic while keeping the current plastic packaging. 
o Possibility to change the packaging material to remove plastic (glass, paper, metal, other materials).

o Possibility to change the package size.

- Possibility to innovate the product in order to reduce the package size.

- Possibility to introduce packaging-free sale of the product.

o Possibility to introduce reuse of the plastic packaging from the product.

o Possibility to recycle packaging from the product.

- Barriers to implementation of the individual types of innovation.

The main respondent of the qualitative research was the process engineer of the company. The information was collected in two stages. Either stage was followed by a check on the completeness of the information collected. Their content analysis followed, which resulted in formulation of conclusions.

\section{Results}

The starting point for finding out the possibilities to reduce the volume of plastic waste for the selected product was to map the innovation process in the company. The results of this research phase are summarized in Table 1.

Table 1. Innovation Process in the Company.

\begin{tabular}{|c|c|c|}
\hline $\begin{array}{l}\text { Characteristics of the innovation } \\
\text { process }\end{array}$ & Application & Form of application \\
\hline $\begin{array}{l}\text { Company's previous interest in product } \\
\text { innovation for sustainability. }\end{array}$ & Yes & $\begin{array}{l}\text { Efforts to reduce the volume of plastic in the } \\
\text { blister, trying to save the plastic fixation material } \\
\text { used in secondary packaging. }\end{array}$ \\
\hline $\begin{array}{l}\text { Respecting stakeholder requirements } \\
\text { when innovating the product and its } \\
\text { packaging. }\end{array}$ & Yes & $\begin{array}{l}\text { In particular, end consumers and wholesalers as } \\
\text { direct customers. }\end{array}$ \\
\hline $\begin{array}{l}\text { Existence of environmental stakeholder } \\
\text { requirements for the product and its } \\
\text { primary packaging. }\end{array}$ & Yes & $\begin{array}{l}\text { Wholesalers, as direct customers, demand to } \\
\text { reduce the volume of packaging plastics. }\end{array}$ \\
\hline $\begin{array}{l}\text { Existence of other environmental } \\
\text { stakeholder requirements. }\end{array}$ & Yes & $\begin{array}{l}\text { Requirement for the AISE logo - proof of } \\
\text { participation in a voluntary association setting } \\
\text { environmental requirements for manufacturers, } \\
\text { products and their packaging. }\end{array}$ \\
\hline $\begin{array}{l}\text { Impact of legislative requirements on the } \\
\text { innovation process of the product and its } \\
\text { packaging in the interest of } \\
\text { sustainability. }\end{array}$ & Yes & $\begin{array}{l}\text { General requirements for REACH chemical } \\
\text { products are set, legislative pressure to reduce } \\
\text { plastics is increasing. }\end{array}$ \\
\hline $\begin{array}{l}\text { Collaboration in the packaging } \\
\text { innovation process. }\end{array}$ & Yes & With packaging manufacturers. \\
\hline
\end{tabular}

After completing the research of the innovation process in the company, various possibilities of saving the plastic used for the primary packaging of the selected product and the obstacles to their application were examined. The results of this research phase are shown in Table 2. 
Table 2. Variants of reducing the volume of plastic waste from the packaging for the selected product.

\begin{tabular}{|c|c|}
\hline $\begin{array}{l}\text { Identified option to reduce } \\
\text { plastic }\end{array}$ & Obstacle to apply the option \\
\hline $\begin{array}{l}\text { Replacement of plastic material } \\
\text { with another type of material } \\
\text { (glass, metal, paper). }\end{array}$ & $\begin{array}{l}\text { Glass is incompatible with the use of the product. } \\
\text { Metal is theoretically usable for the piston and its reuse, but it is a costly } \\
\text { material. Paper would require adjustments, generally layering and } \\
\text { probably supplementation with a foil. }\end{array}$ \\
\hline $\begin{array}{l}\text { Replacement of plastic material } \\
\text { with bioplastic. }\end{array}$ & $\begin{array}{l}\text { Bioplastics decompose to form micro plastics, the environmental benefits } \\
\text { are debatable. }\end{array}$ \\
\hline $\begin{array}{l}\text { Changing the colour of the plastic } \\
\text { packaging for easier recycling. }\end{array}$ & Decreasing the appeal to the end consumer. \\
\hline $\begin{array}{l}\text { Use of recycled plastic in the } \\
\text { production of packaging. }\end{array}$ & $\begin{array}{l}25 \text { percent and higher recycled content in the plastic for packaging } \\
\text { significantly reduces the packaging strength. Recycling companies are } \\
\text { not able to supply recycled materials of sufficient quality to the market. }\end{array}$ \\
\hline $\begin{array}{l}\text { Technological innovation in the } \\
\text { production of packaging - } \\
\text { bubbling. }\end{array}$ & Reduced product aesthetics and functionality. \\
\hline $\begin{array}{l}\text { Increasing the concentration of } \\
\text { the cleaning gel. }\end{array}$ & Reflection in the price of the product unacceptable by customers. \\
\hline $\begin{array}{l}\text { Changing the product form - gel } \\
\text { provided in capsules. }\end{array}$ & Radical reduction of functionality. \\
\hline $\begin{array}{l}\text { Changing the method of sale - } \\
\text { through packaging-free stores. }\end{array}$ & $\begin{array}{l}\text { The need to innovate the product into a liquid form, the problem with } \\
\text { ensuring microbiological safety of the product. } \\
\text { The company does not facilities for washing and disinfecting the } \\
\text { containers; refilling of the containers is not yet technologically mastered. }\end{array}$ \\
\hline $\begin{array}{l}\text { Introduction of plastic packaging } \\
\text { reuse. }\end{array}$ & $\begin{array}{l}\text { The problem is the collection of packaging. } \\
\text { Re-use is uneconomical compared to the use of new packaging (costs of } \\
\text { collection, washing, inspection, storage). Environmental impacts on } \\
\text { wastewater and wash water consumption. }\end{array}$ \\
\hline Application of recycling. & $\begin{array}{l}\text { The company does not have a developed packaging return system or } \\
\text { recycling system. }\end{array}$ \\
\hline
\end{tabular}

\section{Discussion}

The primary qualitative research confirmed some conclusions of previous studies while producing new knowledge. The possibility to save the volume of plastic packaging was confirmed by making the product in a concentrated form as described by Makower and Pike (2009) on the example of P\&G and Atkinson (2008) on the example of Unilever. The possibility reported by Dharmadhikari (2012) to replace plastic with a more environmentally friendly material (bioplastic) was also confirmed. In addition, however, other potential technical, technological and administrative innovations have been identified to reduce plastic packaging: replacement of plastic material with another type of material (glass, paper), change of colour of plastic packaging, use of recycled plastic and technological innovation (bubbling) in production of packaging, change of product form (capsule), sales through zero waste stores, reuse of plastic packaging, and recycling.

However, some of the identified innovation possibilities have such barriers that they are implementable only in theory (replacing plastic with glass or paper). Also, the replacement of plastic with bioplastics is basically out of the question because of the disputable environmental benefit. Other options of plastic primary packaging innovation for a selected product are feasible, but they all represent an increase in operating costs, some of which would also require investment costs. Changing the colour of the plastic container, increasing the concentration of the cleaning gel or changing the form of the product may be considered less expensive. The high costs of innovation would most likely arise from a change in the packaging technology (use of recycled plastic, bubbling) as well as with all innovations that would mean a fundamental change in the reverse flow system (introduction of packaging reuse, recycling) or direct flow system (packaging-free sale).

However, when choosing a suitable innovation option, it is necessary to take into account not only the costs (and expected losses resulting, for example, from the lower value of the product for the 
customer), but also the environmental benefits. The optimal option should ensure the biggest difference between the total environmental benefit and the total costs of innovation (García-Arca et al. 2014).

Various models have been developed to select the optimal variant. These models combine quantitative and qualitative scales to allow bringing subjectivity into the assessment (Grönman et al. 2013). The most commonly used of these models is the model by Olsmats and Dominic (Olsmats and Dominic 2003) "Packaging Scorecard", popular with companies like IKEA and Wal-Mart (García-Arca et al. 2014).

\section{Conclusions}

Packaging is a key element in increasing the sustainability of supply chains and the companies involved (García-Arca et al. 2019). In packaging innovation, product design needs to be integrated with packaging design (García-Arca et al. 2014) as integrated product and packaging decisions make it possible to optimize the overall environmental impact. Innovative activities require the development of cooperation between the company, as the manufacturer of the product, and its business partners, especially the suppliers of packaging. Where the intended innovation affects the substance of the packaged product and/or the management of the direct or reverse material flow through the chain, it is also necessary to involve direct suppliers of inputs and product purchasers. Environmental innovation will then affect a much larger part or even the entire supply chain, or supply network, as the case may be.

The conclusions of the qualitative research carried out can be considered inspiring from the point of view of the identified possibilities of product innovation (not only in the chemical industry) as they were carried out on the basis of exploring possibilities of reducing the plastic packaging of one selected product. This limits the possibility of generalization. Therefore, it is possible to recommend further research, which can be conducted in two ways:

- exploring the possibilities of plastic packaging innovation for other chemical industry products or chemical industry product groups (e.g. detergents, washing and sanitary products); and

- exploring the possibilities of developing collaboration with other partners in the chain to innovate plastic packaging for products of the chemical industry.

In combination with the previous research, follow-up research could significantly contribute to discovering the real possibilities to reduce the volume of plastic packaging, especially for products of the chemical industry.

\section{References}

Abdullah I. Muhammad, Sarfraz Muddassar, Qun Wang, Javaid Neelum. 2018. Drivers of Green Supply Chain Management, LogForum: 14, 437-447. http://dx.doi.org/10.17270/J.LOG.2018.297

Atkinson, William. 2008. Green Packaging: Waste Not, Want Not. Inbound Logistics. July. New York: Keith G. Biondo. Available online: https://www.inboundlogistics.com/cms/article/green-packaging-waste-not-wantnot/ (accessed on 16.10.2019)

Bendul C. Julia, Rosca Eugenia, Pivovarova Darima. 2017. Sustainable Supply Chain Models for Base of the Pyramid. Journal of Cleaner Production: 162, 107-120. https://doi.org/10.1016/j.jclepro.2016.11.001

Bramklev Caroline. 2009. On a Proposal for a Generic Package Development Process. Packaging Technology and Science: an international journal: 22, 171-186. https://doi.org/10.1002/pts.850

Chen Yu-Shan. 2008. The Driver of Green Innovation and Green Image - Green Core Competence. Journal of Business Ethics: 81, 531-543. https://doi.org/10.1007/s10551-007-9522-1

Chen Yu-Shan, Lai Shyh-Bao, Wen Chao-Tung. 2006. The Influence of Green Innovation Performance on Corporate Advantage in Taiwan. Journal of Business Ethics: 67, 331-339. https://doi.org/10.1007/s10551-0069025-5

Dharmadhikari Suyog. 2012. Eco-Friendly Packaging in Supply Chain. The IUP Journal of Supply Chain Management: 9, 7-18. https://search.proquest.com/docview/1434427712?accountid=17239

Dixon-Hardy W. Darron, Curran, A. Baverley. 2009. Types of Packaging Waste from Secondary Sources (supermarkets) - The Situation in the UK. Waste Management: 29, 1198-1207. https://doi.org/10.1016/j.wasman.2008.06.045 
Flint J. Daniel, Larson Everth, Gammelgaard Britta, Mentzer T. John. 2005. Logistics Innovation: A Customer Value-oriented Social Process. Journal of Business Logistics: 26, 113-147. https://doi.org/10.1002/j.21581592.2005.tb00196.x

García-Arca Jesus, González-Portela Garrido T. Alicia, Prado-Prado C. Jose. 2019. Organizational Best Practices in Packaging Design. An Analysis in Perfumery and Cleaning Products. Dirección y Organización: 68, 5-19.

García-Arca Jesus, Prado-Prado C. Jose, Gonzalez-Portela Garrido T. Alicia. 2014. "Packaging Logistics": Promoting Sustainable Efficiency in Supply Chains. International Journal of Physical Distribution $\mathcal{E}$ Logistics Management: 44, 325-346. https://doi.org/10.1108/IJPDLM-05-2013-0112

García-Arca Jesus, Prado-Prado C. Jose. 2008. Packaging Design Model from a Supply Chain Approach. Supply Chain Management:an international journal: 13, 375-380. https://doi.org/10.1108/13598540810894960

González-Boubeta Ivan, Fernández-Vázquez-Noguerol Mar, Domínguez-Caamańo Pablo, Prado-Prado, C. Jose. 2018. Economic and Environmental Packaging Sustainability: A Case Study. Journal of Industrial Engineering and Management: 11, 229-238. https://doi.org/10.3926/jiem.2529

Grönman Kaisa, Soukka Risto, Järvi-Kääriäinen Tehren, Katajajuuri Juha-Matti, Kuisma Mika, Koivupuro HetaKaisa, Ollila Margareetta, Pitkänen Maeja, Miettinen Olli, Silvenius Frans, Thun Rabbe, Wessman Helena, Linnanen Lassi. 2013. Framework for Sustainable Food Packaging Design. Packaging Technology and Science: 26, 187-200. https://doi.org/10.1002/pts.1971

Karia Noorliza, Asaari H. A. H. Muhammad. 2013. Green Innovations in Logistics Industry: Sustainability and Competitive Advantage. In Entrepreneurship Vision 2020: Innovation, Development Sustainability, and Economic Growth, Kuala Lumpur: IBIMA, 456-462.

Liwen Zheng, Juan Zhang. 2010. Research on Green Logistics System Based on Circular Economy. Asian Social Science: 6, 116-119. https://doi.org/10.5539/ass.v6n11p116

Magnier Lise. Schoormans P.L. Jan. 2015. Consumer Reactions to Sustainable Packaging: The Interplay of Visual Appearance, Verbal Claim and Environmental Concern. Journal of Environmental Psychology: 44, 53-62. https://doi.org/10.1016/j.jenvp.2015.09.005

Makower Joel, Pike Cara. 2009. Strategies for the Green Economy: Opportunities and Challenges in the New World of Business. McGraw-Hill.

Meherishi Lavanya, Narayana A. Sushmita, Ranjani K.S. 2019. Sustainable Packaging for Supply Chain Management in the Circular Economy: A review. Journal of Cleaner Production: 237 1-23. https://doi.org/10.1016/j.jclepro.2019.07.057

Mejías M. Ana, Paz Enriue, Pardo E. Juan. 2016. Efficiency and Sustainability through the Best Practices in the Logistics Social Responsibility Framework. International Journal of Operations E Production Management: 36, 164-199. https://doi.org/10.1108/IJOPM-07-2014-0301

Olsmats Carl, Dominic Chris. 2003. Packaging Scorecard - a Packaging Performance Evaluation Method. Packaging Technology and Science: 16, 9-14. https://doi.org/10.1002/pts.604

Saghir Mazen. 2002. Packaging Logistics Evaluation in the Swedish Retail Supply Chain. Lund: Lund University.

Yenipazarli Arda. 2017. To Collaborate or not to Collaborate: Prompting Upstream Eco-Efficient Innovation in a Supply Chain. European Journal of Operational Research: 260, 571-587. https://doi.org/10.1016/j.ejor.2016.12.035

(C) 2019 by the authors. Submitted for possible open access publication under the terms and conditions of the Creative Commons Attribution (CC BY) license (http://creativecommons.org/licenses/by/4.0/). 